Western University

Scholarship@Western

Africa Western Collaborations Day 2020

Abstracts

Africa Western Collaborations Day

2020

Credit Access and Perceived Climate Change Resilience of

Smallholder Farmers in semi-arid Northern Ghana

Evans Batung

University of Western Ontario, ebatung@uwo.ca

Follow this and additional works at: https://ir.lib.uwo.ca/awc_abstracts

Part of the Geography Commons

Citation of this paper:

Batung, Evans, "Credit Access and Perceived Climate Change Resilience of Smallholder Farmers in semiarid Northern Ghana" (2020). Africa Western Collaborations Day 2020 Abstracts. 5.

https://ir.lib.uwo.ca/awc_abstracts/5 


\title{
Credit access and perceived climate change resilience of smallholder farmers in semi-arid northern Ghana
}

\begin{abstract}
Climate change is a major driver of agricultural failure in the Global South. In semi-arid northern Ghana where rain-fed agriculture is the dominant livelihood strategy, climate change is increasingly undermining rural livelihoods. Despite several policy efforts to improve climate adaptation in this context, smallholder farmers' lack of access to credit continues to militate against climate change adaptation. Employing a binary logistic regression and drawing insights from the theory of resilience, this study analyzed data from a cross-sectional survey $(n=1,100)$ in the Upper West Region to examine the relationship between smallholder farmers' access to credit and their perceived climate change resilience. Findings indicate that households with access to formal credit were less likely $(O R=0.63, p \leq 0.05)$ to report good resilience when compared to those without access. Households with formally educated primary farmers were also less likely $(O R=0.50, p \leq 0.01)$ to report good resilience. On the contrary, the poorest households $(O R=6.80, p \leq 0.001)$, and those practicing joint $(O R=2.47, p \leq 0.001)$ were found more likely to report good resilience. These findings highlight that access to credit may not be a standalone tool for strengthening climate change resilience among smallholder farmers. Given the widespread socio-economic vulnerability in this context, this study recommends that agricultural policy must prioritize direct poverty alleviation strategies and integration of indigenous knowledge systems into climate change adaptation strategies, alongside the creation of favorable guidelines related to farmers' credit access, interest rates and credit repayment.
\end{abstract}

Keywords: Resilience; climate change; credit access; smallholder farmers; Upper West Region, Ghana 